\title{
$\mathrm{PH} 102$ actualiad
}

\section{El último congreso de GECA impulsa la creación de una ley andaluza de cultura}

Celebrado en noviembre de 2020, el Congreso de la cultura y la gestión cultural concluyó con una agenda de actuaciones en pro de la renovación y el rescate del sector. La más decisiva: promover una iniciativa legislativa popular (ILP) por una Ley Andaluza de la Cultura. Pero además se adoptaron otras como la creación de un Observatorio de GECA para la gestión cultural andaluza, la elaboración de una propuesta a los poderes públicos para que desarrollen el programa "7×778", así como un estudio comparativo de la legislación laboral francesa y española en el ámbito de la cultura. Por último, se puso de manifiesto la necesidad de caminar hacia la integración efectiva de los servicios culturales en educación, ciencia, turismo, tecnología y salud.

Rafael Morales Astola | Asociación de Profesionales de la Gestión Cultural de Andalucía (GECA)

URL de la contribución <http://www.iaph.es/revistaph/index.php/revistaph/article/view/4805>

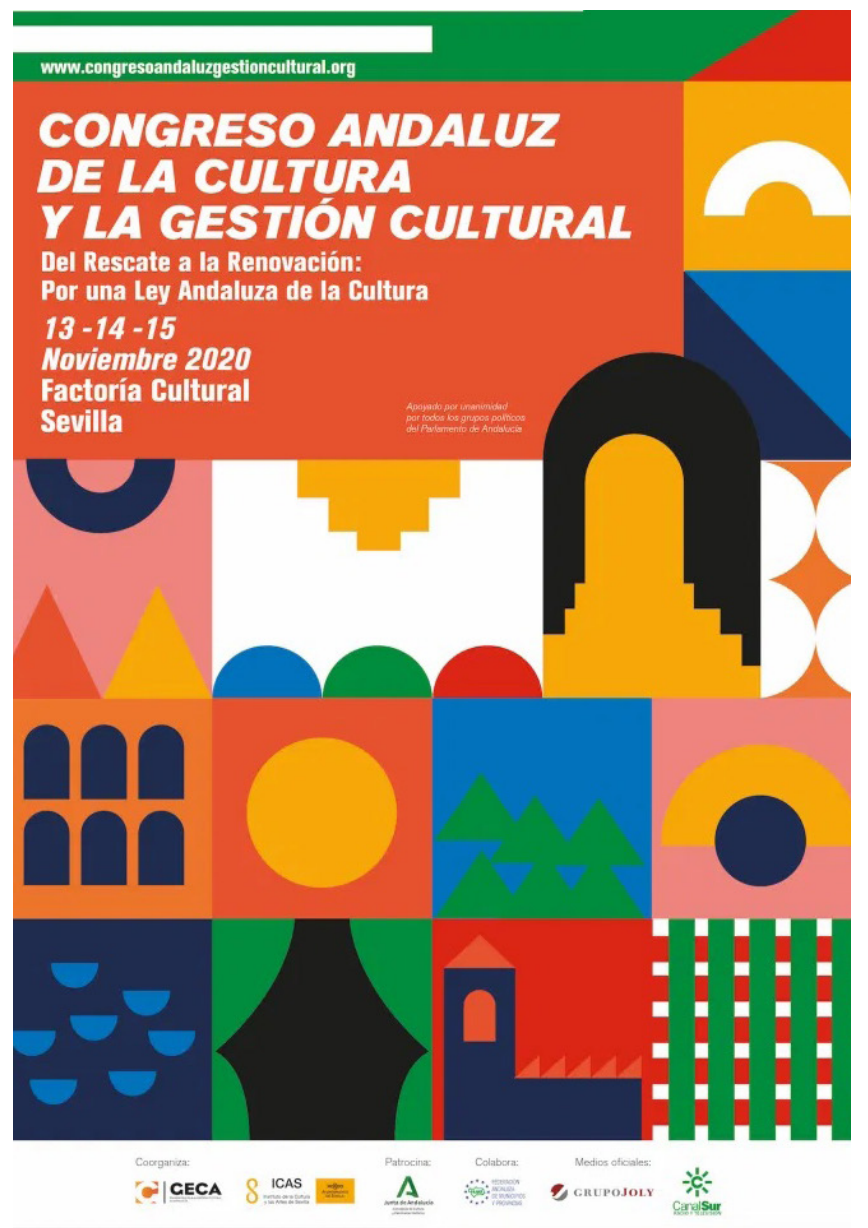

Uno de los resultados del último congreso de gestores culturales de Andalucía, coorganizado por la Asociación de Gestores Culturales de Andalucía (GECA) y el Ayuntamiento de Sevilla-Instituto de las Cultura y las Artes (ICAS), con el patrocinio de la Consejería de Cultura y Patrimonio Histórico de la Junta de Andalucía, ha sido la puesta en marcha de una iniciativa legislativa popular (ILP) que pretende, desde diez ayuntamientos andaluces que sumen un mínimo de 40.000 electores censados, llevar al Parlamento una Proposición de Ley Andaluza de la Cultura.

Este proceso arrancó en marzo de 2019, cuando la nueva Junta Directiva de GECA llevó en su programa promover dicha ley como respuesta a dos situaciones: por un lado, los persistentes efectos de la crisis de 2008 en el sector cultural andaluz; y de otro, la escasa voluntad percibida en los poderes públicos ante lo que parecía el imparable declive de la cultura en Andalucía. Esta doble situación, aún desalentadora, presentaba atisbos positivos que principalmente se debían a la creciente calidad del sector creativo y al empeño de los ayuntamientos que nunca dejaron atrás las programaciones culturales en sus equipamientos, tradiciones y eventos.

El Congreso, que pasó por varias etapas condicionadas sobre todo por la pandemia, adquiría cada vez mayor 


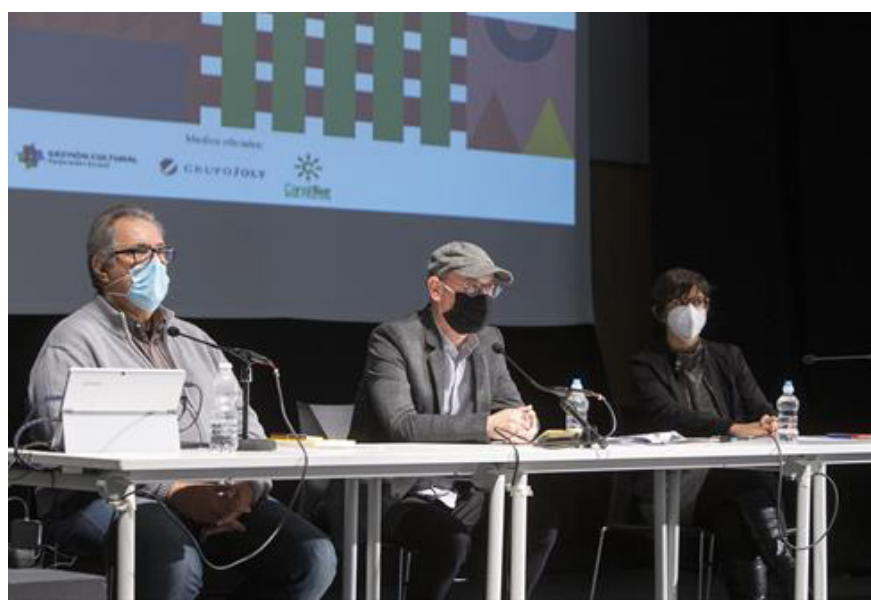

Jornada de conclusiones y clausura del congreso | foto Noletia

necesidad y urgencia. En abril de 2020 se había creado el Grupo de Rescate del Sector Cultural, que ha llegado a integrar a 46 entidades profesionales y empresariales de la cultura andaluza. Este grupo aprobó e hizo púbicas 84 medidas básicas, estratégicas y sectoriales, que impelían a establecer en nuestra comunidad autónoma un marco de seguridad jurídica para la cultura como derecho de la ciudadanía y como recurso de los territorios y las empresas de servicios asociados a la cultura. Ante ello, la opción del Congreso era juntar tres conceptos elementales: rescate, renovación y ley.

Desde el principio el Ayuntamiento de Sevilla, a través del Instituto de la Cultura y las Artes (ICAS), se aprestó a coorganizar el Congreso. La Consejería de Cultura y Patrimonio Histórico de la Junta de Andalucía nos brindó un valioso patrocinio destinado a la comunicación. La Federación Andaluza de Municipios y Provincias (FAMP) colaboraba en la difusión, mientras que Canal Sur y Grupo Joly se convirtieron en los medios oficiales. Anteriormente, el Parlamento Andaluz había aprobado una PNL, presentada por el grupo socialista, en la que todos los partidos parlamentarios apoyaron el Congreso de la Cultura y la Gestión Cultural. Ponentes de gran reputación, como Ania González, Jesús Prieto de Pedro y Juan Antonio Jara, fueron los responsables de darle al Congreso los contenidos principales: respectivamente, filosofía de la ley, contexto legislativo en materia de cultura, y esperanza de los territorios y las empresas.
Además, el comité científico programó una suerte de comunicaciones (deontología profesional, movimiento Alerta Roja, música y museos, formación musical, eurociudades, derechos culturales, cómic, consumo on line en la postpandemia, patrimonio material e inmaterial, enfoque interautonómico en legislación cultural) que ofrecieron una gran diversidad y transversalidad, haciendo las jornadas no sólo más atractivas, sino sobre todo más humanas y completas.

Entre las conclusiones, a la ILP por una Ley Andaluza de la Cultura se sumaron la creación de un Observatorio de GECA para la Gestión Cultural Andaluza, la propuesta a los poderes públicos para que desarrollen el programa "7x778" y ofrezcan más de 30.000 actividades a los municipios andaluces en cualquier día de la semana y en cualquier espacio, el estudio comparativo de la legislación laboral francesa y española en el ámbito de la cultura, y la integración efectiva de los servicios culturales en educación, ciencia, turismo, tecnología y salud.

El observatorio ya está en marcha, cerrando acuerdos con las Diputaciones de Cádiz, Almería y Granada.

Por su parte, y a la espera de que la Consejería de Cultura y Patrimonio Histórico nos responda a una solicitud de reunión, la ILP se encuentra en fase de redacción del documento cero. Esta fase va acompañada de una campaña de participación del sector cultural, el acuerdo con universidades andaluzas para facilitar la textura jurídica en el documento de la segunda fase, y el liderazgo del Ayuntamiento de Sevilla para crear la Comisión Promotora de la Ley y llevar a la Mesa del Parlamento una Proposición de Ley Andaluza de la Cultura participada, impecable y que represente la diversidad de nuestra tierra. De esto modo, la Ley Andaluza de la Cultura alcanzará una doble meta: por un lado, servir como elemento constituyente de las políticas públicas y las estrategias empresariales; por otro, hacer de Andalucía un lugar donde la cultura sea concebida y ejercida como un bien de primera necesidad que defina nuestro presente y nuestro futuro. 